WSRC-TR-2002-00394, REV. 0

Key Words:

Sorption

Zeolites

Sodalite

Cancrinite

Uranium

Retention:

Permanent

\title{
Uranium Sorption on Sodium Aluminosilicates and Gibbsite
}

\author{
Martine C. Duff
}

REPORT DATE OCTOBER 1, 2002

A) Sorption of U on NAS (may facilitate nucleation of $U$ solid phases)

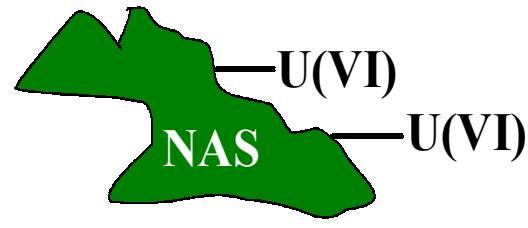

B) Co-precipitation of $U$ within crystalline or amorphous NAS structures

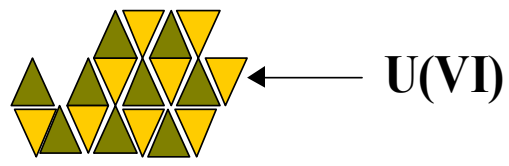

C) Occlusion: growth of $U$ solids on precipitating NAS solids and growth of NAS solids on precipitating $\mathrm{U}$ solids

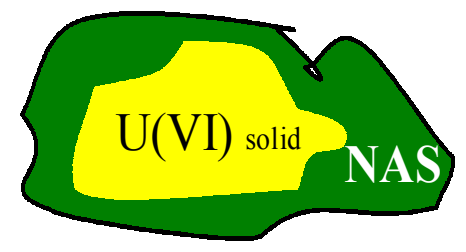

Westinghouse Savannah River Company Savannah River Site Aiken, SC 29808
D) Precipitation of $\mathrm{U}$ as a U(VI) oxide, oxide hydrate, nitrate, or silicate

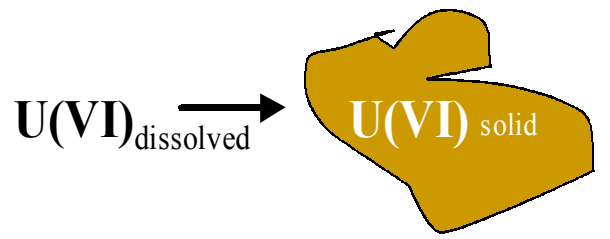

E) Silica sols facilitate greater U pseudosolubility (possible desorption of $U$ from other phases upon silica addition?)

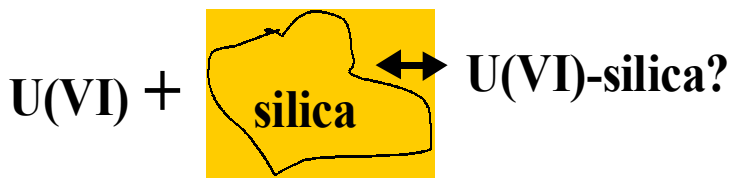


This document was prepared in conjunction with work accomplished under Contract No. DE-AC09-96SR18500 with the U. S. Department of Energy.

\section{DISCLAIMER}

This report was prepared as an account of work sponsored by an agency of the United States Government. Neither the United States Government nor any agency thereof, nor any of their employees, makes any warranty, express or implied, or assumes any legal liability or responsibility for the accuracy, completeness, or usefulness of any information, apparatus, product or process disclosed, or represents that its use would not infringe privately owned rights. Reference herein to any specific commercial product, process or service by trade name, trademark, manufacturer, or otherwise does not necessarily constitute or imply its endorsement, recommendation, or favoring by the United States Government or any agency thereof. The views and opinions of authors expressed herein do not necessarily state or reflect those of the United States Government or any agency thereof.

This report has been reproduced directly from the best available copy.

Available for sale to the public, in paper, from: U.S. Department of Commerce, National Technical Information Service, 5285 Port Royal Road, Springfield, VA 22161, phone: (800) 553-6847, fax: (703) 605-6900

email: orders@ntis.fedworld.gov

online ordering: http://www.ntis.gov/help/index.asp

Available electronically at http://www.osti.gov/bridge

Available for a processing fee to U.S. Department of Energy and its contractors, in paper, from: U.S. Department of Energy, Office of Scientific and Technical Information, P.O. Box 62, Oak Ridge, TN 37831-0062,

phone: (865)576-8401,

fax: (865)576-5728

email: $\underline{\text { reports@ adonis.osti.gov }}$ 


\section{REVIEWS AND APPROVALS}

M. C. Duff, Author, Waste Processing Technology

Date

B. Van-Pelt, Level 4 Manager, Waste Processing Technology

Date

R. E. Edwards, Manager, Process Engineering

Date

W. L. Tamosaitis, Manager, Waste Processing Technology

Date

D. T. Hobbs, Design Check, Waste Processing Technology

Date

Page ii 


\section{TABLE OF CONTENTS}

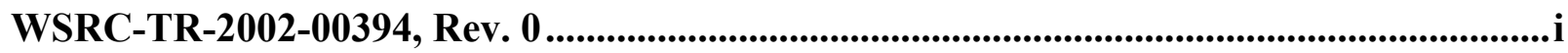

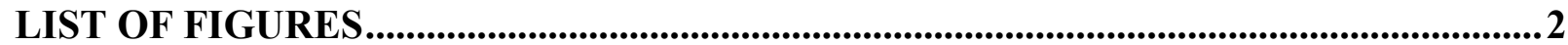

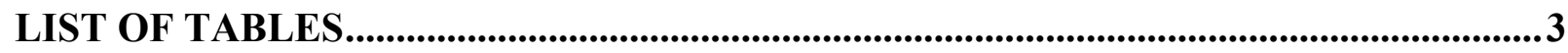

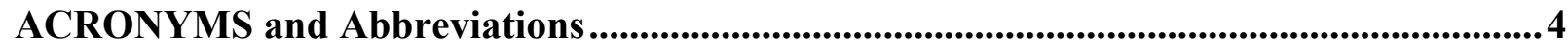

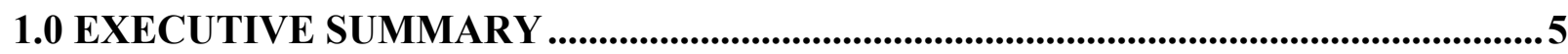

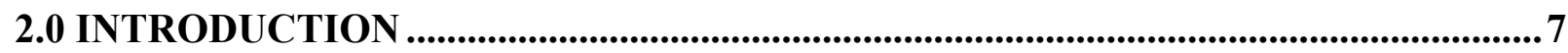

2.1 Potential Routes of U Accumulation with NAS ..................................................... 8

2.2 Review of Sorption Studies with U(VI) and Zeolites ...................................................... 12

3.0 MATERIALS AND EXPERIMENTAL METHODS ................................................14

3.1 Preparation of the NAS and Gibbsite Solids ................................................................ 14

3.2 Salt Solution Preparation ................................................................................................................... 14

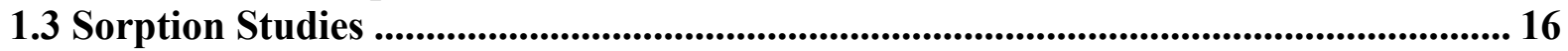

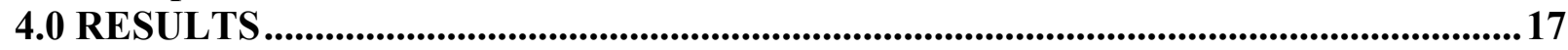

4.1 Sorption Studies ............................................................................................... 17

4.2 Dissolution Processes of Solids in Aqueous Solutions ................................................... 17

4.2.1 Steps of Dissolution and the Reactions that Control Dissolution ........................... 17

4.2.2 Site Reactivity during Dissolution ................................................................................... 19

4.2.3 Quantification of Dissolution Rates.................................................................... 19

4.2.4 Dissolution of NAS and Other Solids in the Tanks Farms.................................. 22

1.1.5 Stability of U Solids in Alkaline Solutions ................................................................... 25

5.0 CONCLUSIONS and recommendations ...........................................................................26

6.0 QUALITY ASSURANCE .........................................................................................26

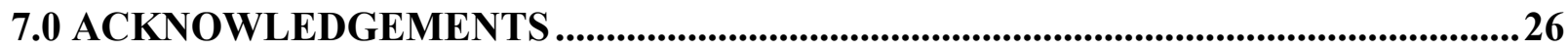

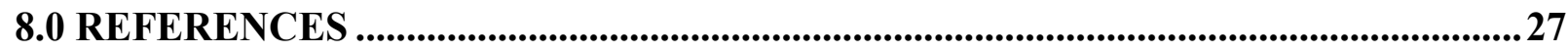




\section{LIST OF FIGURES}

Figure 2.1 Simplified diagram of the types of associations a metal could have with a surface: A) Structural incorporation/co-precipitation, B) Outer-sphere (electrostatic) sorption, C) Specific or inner-sphere sorption and D) Surface precipitation. Blue rings denote first, second and third shell environments that can be probed with X-ray absorption finestructure (XAFS) spectroscopic techniques...................................................................... 9

Figure 2.2 Pictorial representation of possible U interactions with NAS and related solids. .... 11 Figure 4.1 The influence of $\mathrm{pH}$ on the release of $\mathrm{Si}$ from the aluminosilicate anorthite $\mathrm{CaAl}_{2} \mathrm{Si}_{2} \mathrm{O}_{8}, \mathrm{ZPC}$ of 6.8). Simplified and adapted from Amrhein and Suarez (1988). ...... 21

Figure 4.2 The influence of oxalate concentration on the release of $\mathrm{Al}$ from $\delta-\mathrm{Al}_{2} \mathrm{O}_{3}$. The dissolution of $\mathrm{Al}$ increases with increasing oxalate concentration (adsorbed and dissolved) in the system. (Adapted from Furrer and Stumm, 1986).

Figure 4.3 The influence of ligand type on the dissolution rate of $\delta-\mathrm{Al}_{2} \mathrm{O}_{3}$. The dissolution rate changes with respect to the type of ligand. (Adapted from Furrer and Stumm, 1986)........ 24 


\section{LIST OF TABLES}

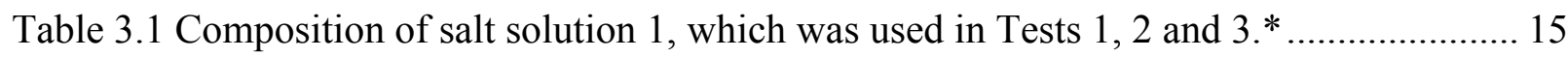

Table 3.2 Composition of salt solution 2, which was used in Test $4{ }^{*}{ }^{*}$................................... 15

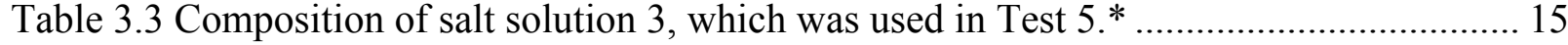

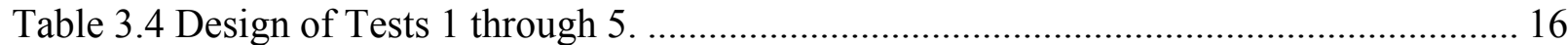

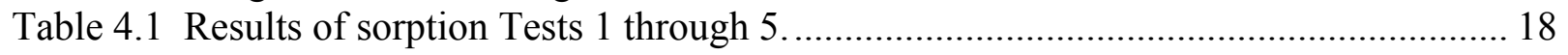

Page 3 of 31 


\section{ACRONYMS AND ABBREVIATIONS}

$\mathrm{Al}$

$\delta-\mathrm{Al}_{2} \mathrm{O}_{3}$

$\mathrm{CaAl}_{2} \mathrm{Si}_{2} \mathrm{O}_{8}$

$\mathrm{Al}(\mathrm{OH})_{3(\mathrm{~s})}$

ADS

$\mathrm{Ca}$

$\mathrm{CaCO}_{3(\mathrm{~s})}$

$\mathrm{CO}_{3}{ }^{2-}$

$\mathrm{CO}_{2(\mathrm{~g})}$

DWPF

$\mathrm{Fe}$

HLW

ICP-MS

$\mathrm{M}$

$\mathrm{Na}$

NAS

$\mathrm{Na}_{8}\left(\mathrm{AlSiO}_{4}\right)_{6} \cdot \mathrm{nH}_{2} \mathrm{O}_{(\mathrm{s})}$

$\mathrm{Na}_{8}\left(\mathrm{AlSiO}_{4}\right)_{6} \cdot \mathrm{nH}_{2} \mathrm{O}_{(\mathrm{s})}$

$\mathrm{Na}_{12} \mathrm{Al}_{12} \mathrm{Si}_{12} \mathrm{O}_{48} \cdot 27 \mathrm{H}_{2} \mathrm{O}_{(\mathrm{s})}$

$\mathrm{MST}$

$\mathrm{C}_{2} \mathrm{O}_{4}{ }^{2-}$

$R_{H}$

SEM

$\mathrm{Si}$

$\mathrm{Sr}$

SRTC

U

U(VI)

WPTS

WSRC

XAFS

XRD

ZPC 
WSRC-TR-2002-00394, REVISION 0

\subsection{EXECUTIVE SUMM ARY}

At the Savannah River Site (SRS), the High-Level Waste (HLW) Tank Farms store and process high-level liquid radioactive wastes from the Canyons and recycle water from the Defense Waste Processing Facility (DWPF). The waste is concentrated using evaporators to minimize the volume of space required for HLW storage. After evaporation, the waste concentrate is transferred to one or more receipt storage tanks. Recently, the $2 \mathrm{H}$ Evaporator was shutdown due to the crystallization of sodium aluminosilicates (NAS) solids that contained elementally enriched uranium $(\mathrm{U})$ precipitates. The scale deposits resided on the evaporator walls and other exposed internal surfaces within the evaporator pot.

Little is known about $U$ interactions with NAS in HLW solutions. Hence, this research was conducted to improve our basic understanding of one possible mechanism for $U$ accumulation in the evaporators and in other SRS process areas. These studies will help support the basis for the continued safe operation of SRS evaporators and provide information on other issues associated with $U$ behavior in the tank farms. For example, the knowledge of such fundamental information could help mitigate $U$ accumulation during evaporator operation and optimize saltcake dissolution.

To examine the interaction of $U$ with NAS solids, tests were conducted to evaluate the sorptive affinity of $U$ for the following well-characterized NAS phases: sodalite, cancrinite, zeolite A, amorphous zeolite precursor and a silicon ( $\mathrm{Si}$ )-free aluminum (Al)-containing phase called gibbsite (all solids will be referred to as NAS solids for simplicity).

The studies and a review of the literature yield the following information:

- With the exception of cancrinite $(\mathrm{s})$, the NAS solids were highly soluble in the U-containing salt solutions that did not contain elevated levels of dissolved Al or Si. Cancrinite and gibbsite were not subject to dissolution in solutions containing dissolved $\mathrm{Al}$ and $\mathrm{Si}$.

Previously published studies indicate the sorption of $U$ on zeolites is a rapid processoccurring in time periods as short as within 15 minutes of contact. ${ }^{1,2}$ These studies used similar, but different NAS materials and solutions exhibiting much lower alkalinity and ionic strengths than that tested in this study. Since rapid adsorption occurred in the reported tests, we analyzed solution samples after short contact times to determine if sorption was occurring over the short term. No evidence of uranium removal could be detected from the filtered solution samples suggesting that sorption was not occurring during the early contact times. However, given the dissolution of all the NAS materials except for cancrinite and gibbsite in contact with solutions containing dissolved aluminum and silicon, we cannot conclusively determine with the available data that sorption of uranium is not occurring with sodalite, zeolite $\mathrm{A}$ and the amorphous zeolite precursor materials. We recommend that additional tests be conducted at conditions that prevent the dissolution of the NAS solids to provide conclusive evidence that sorption of uranium is not a significant removal mechanism under highly alkaline conditions.

- One or more mechanisms other than sorption are most likely responsible for U

Page 5 of 31 
accumulation in the presence of NAS solids. Options include precipitation of U solids (as U oxides, hydroxides, and silicates), co-precipitation with NAS (i.e., structural incorporation of $U$ with in the NAS structures) and the physical entrainment (specifically, occlusion) of U solids by NAS solids (or the physical entrainment of NAS solids by U solids).

- The dissolution of some of the NAS solids that was observed has relevance to how $\mathrm{U}$ may have concentrated in the $2 \mathrm{H}$ evaporator. This requires an assumption that NAS solids [or the conditions that are required to form large amounts of "sticking" NAS solids] also initiate the formation of $\mathrm{U}$ solids in the evaporator. The rapid dissolution of some of the NAS solids observed during the sorption studies (in this document) indicates that some of the NAS solids in an evaporator can undergo dissolution once a new "dilute" feed (i.e., one that is low in dissolved $\mathrm{Al}$ and $\mathrm{Si}$ or one that is low in $\mathrm{Al}$ or low in $\mathrm{Si}$ ) or flush water is introduced. If solid phase forms of $\mathrm{U}$ (oxides, hydroxides, silicates etc.) form and are resistant to dissolution, $\mathrm{U}$ solids could accumulate over time - particularly because most feeds are likely to contain dissolved $U$ concentrations that are at or close to saturation. In contrast, some NAS solids such as cancrinite and gibbsite (or other Al oxyhydroxides) could also accumulate with the $\mathrm{U}$ because they are more resistant to dissolution than other NAS solids such as sodalite. It is also possible that some more soluble NAS solids become occluded by less soluble forms. 
WSRC-TR-2002-00394, REVISION 0

\subsection{INTRODUCTION}

At the Savannah River Site (SRS), the High-Level Waste (HLW) Tank Farms store and process high-level liquid radioactive wastes from the Canyons and recycle water from the Defense Waste Processing Facility (DWPF). The waste is concentrated using evaporators to minimize the volume of space required for HLW storage and after evaporation, the waste concentrate is transferred to one or more receipt storage tanks. The $2 \mathrm{H}$ Evaporator was recently shutdown due to the accumulation of sodium aluminosilicates (NAS) (made of sodalite $\left[\mathrm{Na}_{8}\left(\mathrm{AlSiO}_{4}\right)_{6}\right.$. $\left.\mathrm{nH}_{2} \mathrm{O}_{(\mathrm{s})}\right]$, cancrinite $\left[\mathrm{Na}_{8}\left(\mathrm{AlSiO}_{4}\right)_{6} \cdot \mathrm{nH}_{2} \mathrm{O}_{(\mathrm{s})}\right]$, zeolite A $\left[\mathrm{Na}_{12} \mathrm{Al}_{12} \mathrm{Si}_{12} \mathrm{O}_{48} \cdot 27 \mathrm{H}_{2} \mathrm{O}_{(\mathrm{s})}\right]$, various potential zeolite precursor materials in addition to gibbsite $\left.\left[\mathrm{Al}(\mathrm{OH})_{3(\mathrm{~s})}\right]\right)$ scale that was enriched in uranium $(\mathrm{U}) .{ }^{3}$ The scale resided on the evaporator walls and other exposed internal surfaces within the evaporator pot. The scale was identified to consist of a 50:50 mixture of cancrinite [with a chemical formula of $\mathrm{Na}_{8} \mathrm{Al}_{6} \mathrm{Si}_{6} \mathrm{O}_{24}\left(\mathrm{NO}_{3}\right)_{2} \cdot 4 \mathrm{H}_{2} \mathrm{O}$ ] and sodalite, aluminum hydroxide and sodium diuranate. ${ }^{4}$

The formation of the U-rich NAS-containing scale has been attributed to the source of the evaporator feed, which was elevated in silicon (Si), aluminum (Al), low in hydroxide, high in $\mathrm{U}$ and saturated with respect to sodium diuranate [as described by Jantzen et al. (2001); (2002) and references therein]. ${ }^{4,5}$ The particular feed, which came from the DWPF recycle stream was routed to the evaporator during 1997 and 1999. During this period, clogging of the gravity drain line occurred twice. Clogging of the gravity drain line could have been due to long residence times ${ }^{6}$ in addition to the nature of the feeds, which were sent to the evaporator. The feed that contained recycle from the DWPF was often rich in colloidal (turbid) material, low in hydroxide concentration (relative to the other SRS evaporator feeds) and low in specific gravity. ${ }^{4,5}$ The feed pump for the evaporator was positioned in a low part of the feed tank, which consisted of a zone of turbidity, which was associated with high Si. This material was thought to promote the precipitation and deposition of NAS solids in the evaporator. ${ }^{4,5}$ To unplug the gravity drain line and other parts of the system, flush water was used to remove the clogging and consequently, large spikes in dissolved Si were observed in the drop tank and feed tank subsequently after flushing. These frequent flushes with water occurred in the feed tanks, drop tank and evaporator. The flushes disturbed the depth stratification of the feed tank (i.e., the zone of turbidity) and promoted a more mixed system, with respect to Si content. It is possible that some dissolution of NAS solids occurred during this flushing period.

Mass balance calculations indicate that roughly 89 percent of the $U$ that entered the evaporator over a 2-year period prior to shutdown remained in the evaporator whereas less than 10 percent of the Al and Si that was sent to the evaporator remained in the evaporator. ${ }^{7}$ Evaporation of solutions containing uranium can produce concentrated waste solutions that are supersaturated in uranium. Under the highly alkaline conditions, sodium diuranate is the thermodynamically favored solid phase of uranium and will precipitate from supersaturated alkaline salt solutions. ${ }^{8}$ The quantity of uranium sent through the $2 \mathrm{H}$-evaporator during the 2 -year period is representative of that processed historically. Thus, the effective removal of almost $90 \%$ of the uranium during this time period appears associated with the formation of NAS solids. However the exact mechanism for accumulation of the uranium is not understood. Precipitation of NAS solids is likely when solutions containing Si and Al are evaporated

Page 7 of 31 
because the solution concentrations of these species increase. Therefore, the formation of solids during typical evaporation conditions should be expected. ${ }^{\text {a }}$ Operation of the evaporator prior to 1997 did not produce the significantly high quantities of scale that were observed prior to shutdown. This suggests that in general, most of the solids that form during evaporator operation prior to 1997 were removed from the evaporator and scale buildup was somewhat minimal.

However, if precipitation of $U$ coincides with the precipitation of NAS solids and most of the NAS solids are readily removed (as indicated by the mass balance calculations), the U would have been removed from the evaporator along with the NAS solids. In contrast to what has been observed during operation of the evaporator in previous years, $U$ became concentrated with NAS on the walls of the $2 \mathrm{H}$ evaporator during the NAS scale build-up. This concentration of $U$ in the evaporator may have been due to the low hydroxide concentration of the feed as described by Jantzen et al. (2001); (2002) and references therein]. ${ }^{4} 5$ It is thought that higher hydroxide levels promote the suspension of $U$ solids - making them less likely to remain (i.e., deposit) in the evaporator and more likely to be routed to the drop tank with the evaporated waste concentrate. This potential mechanism of deposition should be studied further.

\subsection{Potential Routes of U Accumulation with NAS}

Uranium accumulation during the evaporation of HLW is a potential criticality riskparticularly if the incoming waste is enriched in ${ }^{235} \mathrm{U}$. During evaporation, several processes may contribute to the accumulation of U-containing solids as shown pictorially in Fig. 2.1 and 2.2. [Note: Fig. 2.1 demonstrates potential U interactions with NAS on the molecular scale whereas Fig. 2.2 shows more of a conceptual or cartoon-like diagram of potential U interactions with NAS solids.] This report will operationally define the various uptake mechanisms according to the following text.

Uptake processes by solids can occur by several mechanisms: structural incorporation, ion exchange (electrostatic or outer-sphere) sorption, specific adsorption and surface precipitation. Fig. 2.1 provides a schematic of these processes. Many of these terms have been used loosely in the literature and their use varies with scientific discipline. This report focuses on NAS surfaces and their interaction with U. A more thorough review of these processes that that presented in the following paragraphs is presented elsewhere. ${ }^{9,10}$ The expression of these uptake processes typically depends upon the amount of metal added, solution and solid phase characteristics.

"Ion exchange" can have different meanings, which results in some confusion in the literature. One very general way to express ion exchange is Structural Incorporation, which is the substitution of a solution species for a structural atom as shown in the example below for strontium $(\mathrm{Sr})$ ion substitution for calcium $(\mathrm{Ca})$ ion in calcite [calcium carbonate, $\mathrm{CaCO}_{3(\mathrm{~s})}$ ].

$$
\mathrm{CaCO}_{3(\mathrm{~s})}+\mathrm{Sr}^{2+} \rightleftarrows \mathrm{SrCO}_{3(\mathrm{~s})}+\mathrm{Ca}^{2+}
$$

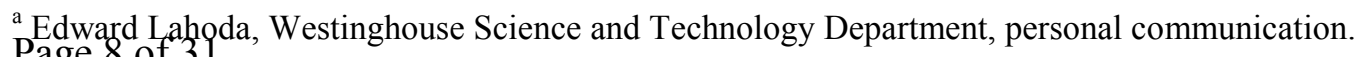
Page 8 of 31
} 


\section{Molecular/Atom Scale Metal Interactions with Surfaces}
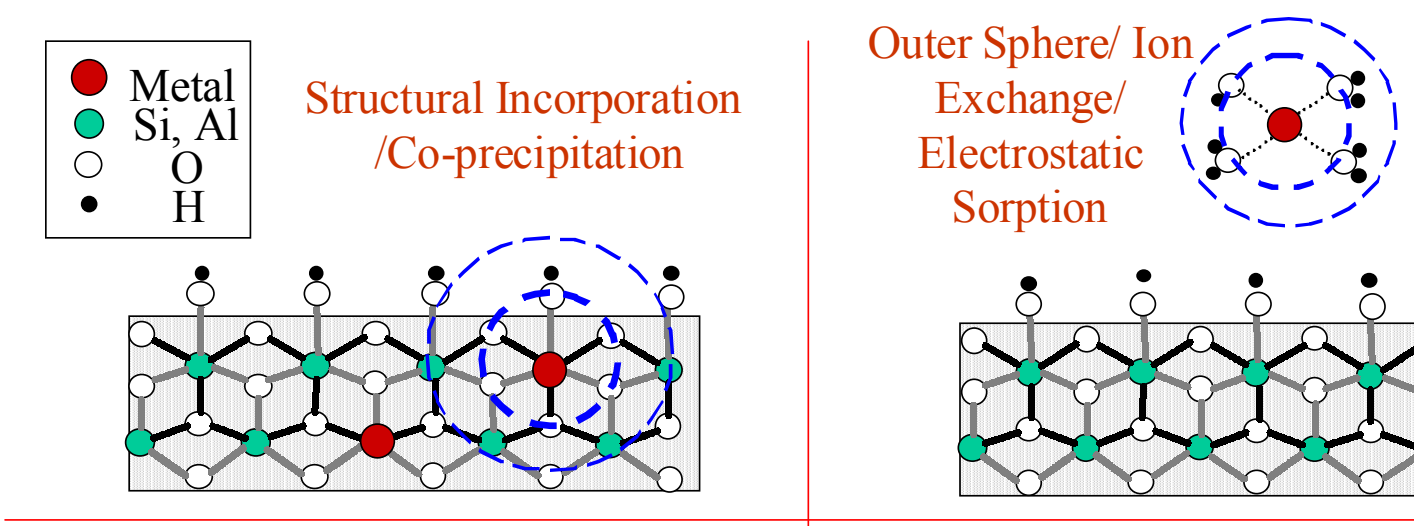

Specific Adsorption/ Chemisorption / Inner Sphere Sorption
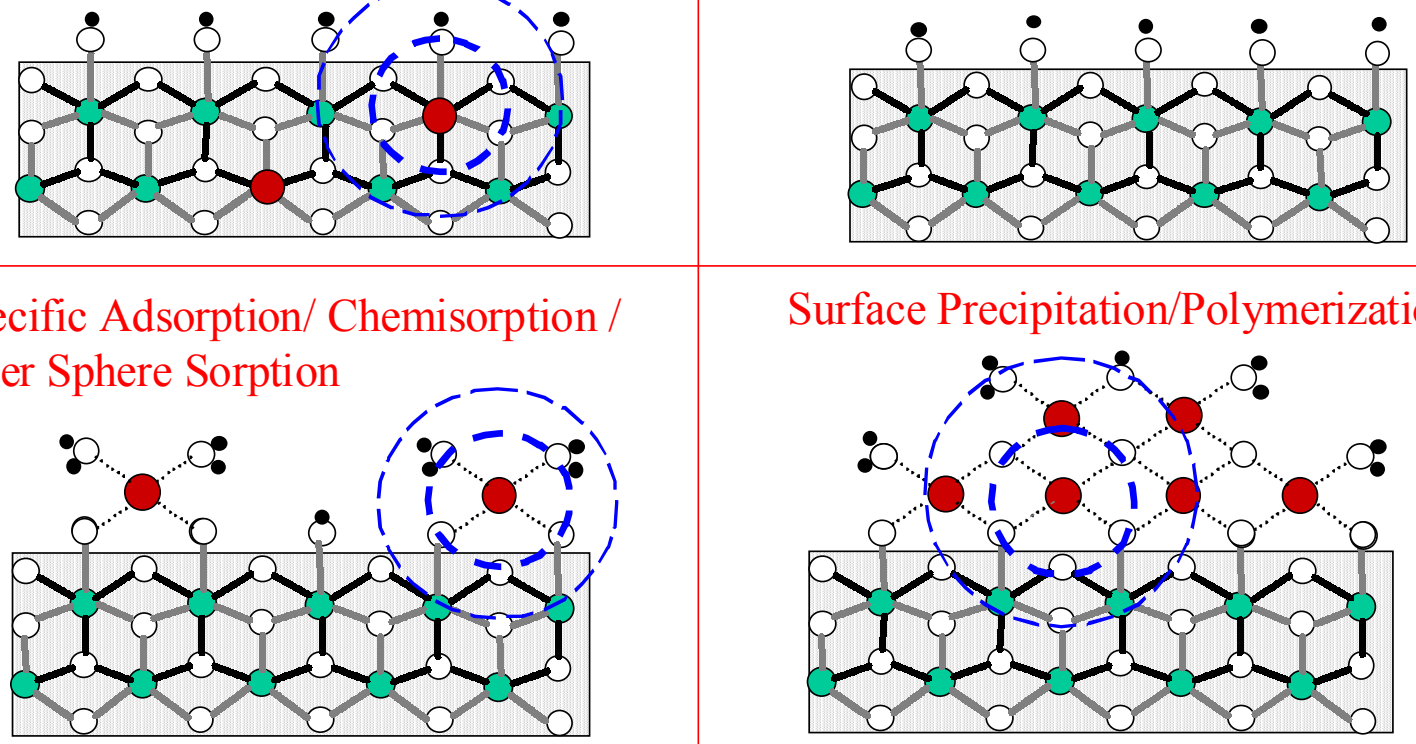

Surface Precipitation/Polymerization

Blue circles denote coordination shells.

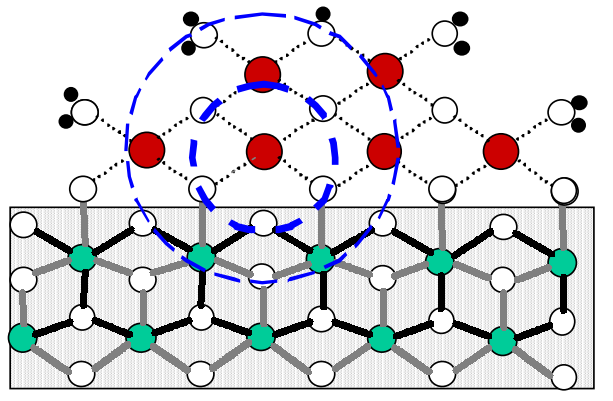

Figure 2.1 Simplified diagram of the types of associations a metal could have with a surface: A) Structural incorporation/co-precipitation, B) Outer-sphere (electrostatic) sorption, C) Specific or inner-sphere sorption and D) Surface precipitation. Blue rings denote first, second and third shell environments that can be probed with X-ray absorption fine-structure (XAFS) spectroscopic techniques. 
This type of metal uptake typically requires ready access to structural atoms. One example of this process would be the exchange of $\mathrm{Na}^{+}$for $\mathrm{Ca}^{2+}$ within the interlayer region of a layered metal oxide solid. Structural incorporation also involves co-precipitation, where a new atom substitutes for one or more of the host atoms in a structure. Ideally, structural incorporation of anions could also result in a similar number of neighboring atoms in the first coordination shell to that of the replaced ion prior to its release. Therefore, the local environment of the exchanged atom would tend to resemble the environment the newly exchanged atom had before its release (Fig. 2.1A). Two exceptions to this would be when the host structure is a nanoparticle and when the structure is amorphous. In these cases, exact determinations of whether the participating metal species resides in a structural vacancy or within an interlayer site are not straightforward. ${ }^{11}$

Ion Exchange in a more restrictive sense as used in this report is an electrostatic process involving the replacement of one readily exchangeable hydrated ion by another similarly exchangeable ion (Fig. 2.1B). This type of sorption is also referred to as Outer Sphere sorption. Ion exchange does not involve the formation of bonds on the participating surface because the sorbed ion is only present in the diffuse double layer (DDL). This type of outer sphere sorption is normally reversible ${ }^{12}$ and is a function of ionic strength (i.e., such as $\mathrm{Na}^{+}$ion concentration). At high ionic strengths, the DDL collapses and less sorption by ion exchange is observed than at low ionic strengths. Ion exchange sorption is often associated with materials that have constant surface charge and exhibit no change in overall surface charge upon ion exchange sorption. An example of this process would be exchange of hydrated $\mathrm{Na}^{+}$ion for hydrated $\mathrm{UO}_{2}{ }^{2+}$ in the DDL.

Specific adsorption involves the formation of predominantly covalent bonds with the surface, but the bonds can have some ionic behavior. This type of sorption is often referred to as Chemisorption or Inner Sphere sorption. Specifically adsorbed metals typically have one or more atoms from the participating surface in the second coordination shell (Fig. 2.1C). This type of sorption involves the release of $\mathrm{H}^{+}$or structural surface ions (such as $\mathrm{Na}^{+}$in monosodium titanate or MST) upon sorption. For example, specific sorption of $\mathrm{UO}_{2}{ }^{2+}$ to NAS could result in the presence of $\mathrm{Si}$ and $\mathrm{Al}$ atoms in the second coordination shell of the $\mathrm{UO}_{2}{ }^{2+}$. Specific adsorption is usually irreversible. ${ }^{12}$ However, in the literature, specific adsorption is not always differentiated from structural incorporation or surface precipitation. Specific adsorption may involve mononuclear complexes or polymeric species. Specific adsorption may occur with metals and their associated ligands (such as a U(VI)-carbonate ion) and specific adsorption is influenced by other solution- and surface-related variables. ${ }^{13}$

Surface Precipitation occurs by nucleation of new solid phase on a host surface (Fig. 2.1D). For example, when the concentration of a dissolved metal such as $\mathrm{UO}_{2}{ }^{2+}$ is high enough to result in the super-saturation of one or more $\mathrm{UO}_{2}{ }^{2+}$-containing phases [such as $\mathrm{U}(\mathrm{VI}) \mathrm{O}_{3}{ }^{\circ}$ $\left.2 \mathrm{H}_{2} \mathrm{O}_{(\mathrm{s})}\right]$ in the presence of another solid (such as NAS), the other solid facilitates the nucleation of the new solid $\mathrm{UO}_{2}{ }^{2+}$-rich phase. This U-rich material would have numerous $\mathrm{U}$ atoms in the second coordination shell of the $U$. The sorption of colloidal (polymeric) $U$ species on surfaces would resemble the same local environment (on the atom scale) as observed for surface precipitation. When atoms from a potential host surface are absent and polymeric species are present, the mechanism of $U$ removal from solution is likely to be direct

Page 10 of 31 
A) Sorption of U on NAS (may facilitate nucleation of $U$ solid phases)

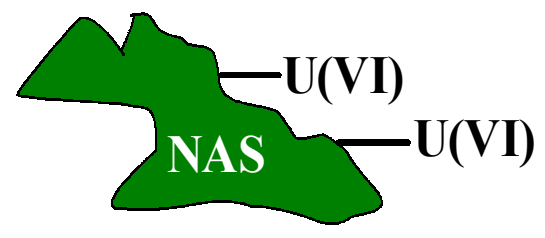

B) Co-precipitation of $U$ within crystalline or amorphous NAS structures

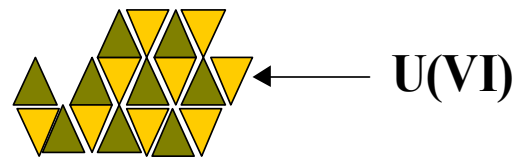

D) Precipitation of U as a U(VI) oxide, oxide hydrate, nitrate, or silicate

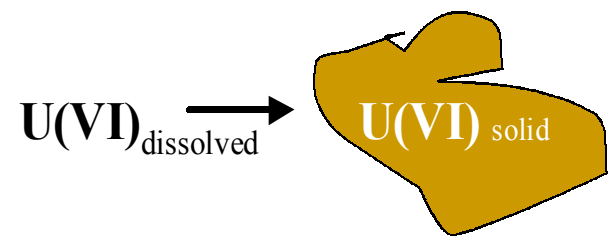

E) Silica sols facilitate greater U pseudosolubility (possible desorption of $U$ from other phases upon silica addition?)

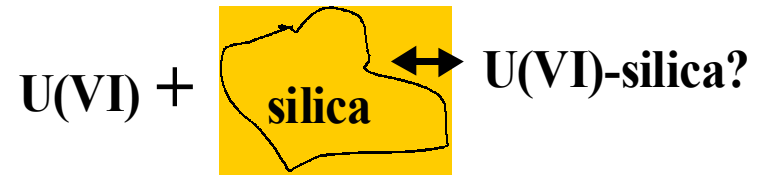

C) Occlusion: growth of $U$ solids on precipitating NAS solids and growth of NAS solids on precipitating $\mathrm{U}$ solids

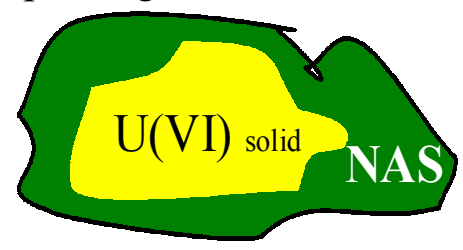

Figure 2.2 Pictorial representation of possible U interactions with NAS and related solids. 
precipitation.

Uranium may be concentrated by sorption to the surfaces of the NAS and other related solids that can form in the evaporators. These processes are illustrated in a more simplistic manner in Fig. 2-2, which is emphasizes the potential interactions U can have with NAS. Sorption can be divided into two types of molecular scale sorption-related processes and it involves the uptake of atoms near or at a participating sorptive surface (Fig. 2.2A). An element such as $U$ could co-precipitate with the NAS and related solids as shown pictorially in Fig. 2.2B. [For zeolites, the term co-precipitation could be sub-divided to include uptake into zeolite channels and any isomorphic substitution (i.e., of $\mathrm{U}$ for $\mathrm{Si}$ or $\mathrm{Al}$ ) in the zeolite structure. ${ }^{14}$ ] Uranium could also deposit by precipitation via surface nucleation (often referred to as chemical seeding) on NAS minerals (Fig. 2.2C). It is also possible that U solids could seed the growth of NAS solids (Fig. 2.2C). The $\mathrm{U}$ could potentially precipitate as a oxide [such as $\mathrm{UO}_{3(\mathrm{~s})}$ ], a hydrous oxide [such as $\mathrm{Na}_{2}\left(\mathrm{UO}_{2}\right)_{3} \mathrm{O}_{3} \cdot(\mathrm{OH})_{2(\mathrm{~s})}$ ], and a silicate [e.g., $\left(\mathrm{UO}_{2}\right)_{2} \mathrm{SiO}_{4} \cdot 2 \mathrm{H}_{2} \mathrm{O}_{(\mathrm{s})}$ and $\mathrm{Na}_{4}\left(\mathrm{UO}_{2}\right)_{2} \mathrm{Si}_{4} \mathrm{O}_{10} \cdot$ $4 \mathrm{H}_{2} \mathrm{O}_{(\mathrm{s})}$ ] (Fig. 2.2D). ${ }^{15,16}$ Precipitation of $\mathrm{U}$ could occur simultaneously with the precipitation of NAS solids. This process is referred to as solid phase nucleation. ${ }^{9}$ The precipitation of U may also occur independent of NAS formation. A molecular scale view of an example of a $U$ precipitate is not presented in Fig. 2.2. However, a crystalline $U$ form not associated with another separate mineral surface would be identifiable based on its crystal structure and the positions and identities of the atoms in that structure. This information is obtained from structural refinements of X-ray diffraction (XRD) data and from XAFS data.

Uranium may also interact with silica sols, which have no defined crystal structure because of their amorphous nature (Fig. 2.2E). This interaction could possibly enhance U solubility by forming U-silica colloids, which appear (by analysis) to be dissolved because they are too small to be isolated by solution filtration. On an atom or molecular scale basis, this type of interaction with $U$ is best be described by the description of structural incorporation in Fig. 2.1A, which shows $\mathrm{U}$ in a crystalline structural-type environment. However, for colloidal Si, which is often very amorphous, the local environment of the $U$ would not resemble an environment that has a crystalline structure.

\subsection{Review of Sorption Stud ies with U(VI) and Zeolites}

Several solid phases or sorbents such as the titanates (such as monosodium titanate or MST) and $\mathrm{Mn}$ oxides concentrate actinides and other radionuclides under conditions that are similar to alkaline HLW salt solutions. ${ }^{17,18,19,20}$ At high $\mathrm{pH}$, the surfaces of most solids are negatively charged and likely to sorb cationic species, such as $\mathrm{Sr}^{2+}$. Under these solution conditions most actinides such as $\mathrm{U}(\mathrm{VI})$ exist as negatively charged hydrolysis and carbonate $\left(\mathrm{CO}_{3}{ }^{2-}\right)$ species [such as $\left(\mathrm{UO}_{2}\right)_{2}(\mathrm{OH})_{5}{ }^{-}$and $\left.\mathrm{UO}_{2}\left(\mathrm{CO}_{3}\right)_{3}{ }^{4-}\right]^{21}$ When these $\mathrm{U}(\mathrm{VI})$ species dominate the solution speciation (at high $\mathrm{pH}$ or in high $\mathrm{CO}_{3}{ }^{2-}$ solutions), $\mathrm{U}(\mathrm{VI})$ typically has a low affinity for certain solids, such as the Fe oxides. ${ }^{22,23}$ The sorption of U(VI) species among other actinide species on sorbents such as the titanates occurs to a limited extent at high $\mathrm{pH}$. The mechanisms by which these processes occur with titanates, which are likely to be negatively charged are not known although some information exists. ${ }^{24}$ Sorption studies with U(VI) typically demonstrate that it has low affinity for zeolites (such as zeolite $\mathrm{X}$ and clinoptilolite) at high $\mathrm{pH}$ (9-11) particularly in the presence of elevated inorganic carbon. ${ }^{1,25}$ This is because the higher levels Page 12 of 31 
of inorganic carbon favor the formation of negatively-charged, highly soluble U(VI)-carbonate complexes, which have low affinities for similarly-charged surfaces. Studies with zeolite X indicate that uptake of $U$ decreases with increasing temperature at high solution $U$ concentrations. ${ }^{1}$ Some of the sorption studies with $\mathrm{U}$ do not reveal the ionic strength of the solutions used ${ }^{1}$ whereas other studies report doing their studies at $0.1 \mathrm{M}^{25,26}$ Sorption studies with HEU-type (heulandite and clinoptilolite) zeolites and excessively high initial U solution concentrations (i.e., $20 \mathrm{~g} \mathrm{U} \mathrm{L}^{-1}$ ) report that multiple uptake mechanisms were operative: including ion exchange (outer sphere sorption), specific adsorption and precipitation (of $\mathrm{U}$ ). ${ }^{27}$ These studies also concluded that the mechanism of uptake was $\mathrm{pH}$-dependent. Few (if any) sorption studies have been done with $\mathrm{U}$ and zeolites above $\mathrm{pH}$ 12. Spectroscopic studies with silicate gels indicate that $\mathrm{U}$ sorbs via edge sharing with silica tetrahedra. ${ }^{28}$ This type of

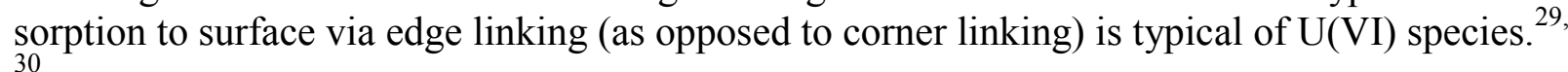

This research with $\mathrm{U}$ and NAS solids was conducted to contribute to the current understanding of $\mathrm{U}$ accumulation with NAS and Al hydroxide solids in the evaporators and in other process areas at the SRS that may concentrate $U$ in the presence of these phases. The focus of this report is to examine what relative affinity U(VI) has for some of the NAS solids that exist in evaporators and in saltcake and to discuss the behavior of U and NAS solids in highly alkaline solutions. This work is part of a larger research effort, which involves additional work by researchers at SRTC and Oak Ridge National Laboratory. Information obtained from this effort will help provide information to help mitigate U-rich scale formation during the evaporation and handling of HLW at the SRS.

Page 13 of 31 
WSRC-TR-2002-00394, REVISION 0

\subsection{MATERIALS AND E XPERIMENTAL METHODS}

\subsection{Preparation of the NAS and Gibbsite Solids}

The NAS and gibbsite were synthesized and provided by Professor Addai Mensah at the University of South Australia. The details of the syntheses and the solids characterization are provided in Mensah et al. (2002). ${ }^{31}$

\subsection{Salt Solution Preparation}

Testing required the preparation of several HLW simulant salt simulant solutions as shown in Tables 3.1, 3.2 and 3.3. The salt solutions from Tests 1,2 , and 3 were spiked with known levels of U(VI) at approximately $0.23,0.72$, and $5.32 \mathrm{mg} \mathrm{U} \mathrm{L}^{-1}$ (respectively). Solutions 4 and 5 were spiked with known levels of U(VI) at approximately 0.16 and $0.23 \mathrm{mg} \mathrm{U} \mathrm{L}^{-1}$ (respectively) each. The U(VI) came from stock solutions that were made using solid phase uranyl nitrate hexahydrate. The salt solutions were made using an acidic preparation method as discussed in Duff et al. (2002). ${ }^{18}$ The salt solutions (from Tests 1, 2, 4 and 5) were made under ambient conditions. The Test 3 solution was made in a plastic glovebag that contained a nitrogen gas headspace. The salt solutions were then allowed to equilibrate for 24 hours prior to filtering with a 0.45 -micron nylon filter. A nitrogen headspace was selected to limit the introduction of atmospheric carbon dioxide gas $\left[\mathrm{CO}_{2(\mathrm{~g})}\right]$, which could potentially influence the sorption and speciation behavior of U(VI) in the salt solutions. ${ }^{23,32}$ After all of the salt solutions were filtered, they were stored in plastic bottles that were tightly capped to limit the introduction of atmospheric $\mathrm{CO}_{2}$. The first set of salt solutions (Tests 1 through 3 ) consisted of 6 molar $(\mathrm{M}) \mathrm{Na}^{+}$as shown in Table 3.1. The second solution (Test 4) consisted of $6 \mathrm{M} \mathrm{Na}^{+}$ with additional dissolved $\mathrm{Al}$ as in Table 3.2.

The salt solution from Test 5 consisted of $5.6 \mathrm{M} \mathrm{Na}^{+}$(see Table 3.3), but this solution was not spiked with U upon initial preparation. Prior to spiking with U(VI), this salt solution was split up into six-250 mL volumes. Each $250-\mathrm{mL}$ volume of this salt solution was given $10 \mathrm{~g}$ of NAS solid $\mathrm{L}^{-1}$ of one of the NAS solids (amorphous zeolite precursor, zeolite A, sodalite, cancrinite and gibbsite). These NAS-solution mixtures were placed on a circulating oven shaker at room temperature for 7 days to allow the solids to dissolve in their respective solutions. However, the solutions were not analyzed so the solutions may not have been at thermodynamic equilibrium. [This pre-equilibration step was performed to help saturate the salt solutions with respect to $\mathrm{Al}$ and $\mathrm{Si}$ so that the dissolution of the NAS solids during the sorption experiments would be minimized.] ${ }^{33}$ After 7 days, the salt solution-NAS mixtures to be used in Test 5 were

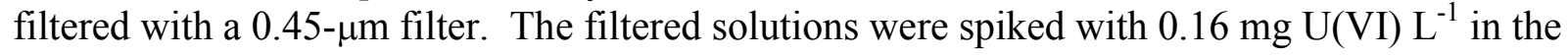
absence of the NAS solids. After spiking, all solutions were used in sorption studies within three weeks of preparation. 
Table 3.1 Composition of salt solution 1, which was used in Tests 1, 2 and 3.*

\begin{tabular}{|c|c|}
\hline Component & Concentration (M) \\
\hline $\mathrm{NaNO}_{3}$ & 1.0 \\
\hline $\mathrm{NaOH}$ & 4.0 \\
\hline $\mathrm{NaNO}_{2}$ & 1.0 \\
\hline Total Na & 6.0 \\
\hline
\end{tabular}

* The levels of $\mathrm{Al}$ (and $\mathrm{Si}$ ) in these solutions were probably higher at the end of the sorption tests due to the dissolution of some of the NAS solids used in the testing.

Table 3.2 Composition of salt solution 2, which was used in Test 4.*

\begin{tabular}{|c|c|}
\hline Component & Concentration (M) \\
\hline $\mathrm{NaNO}_{3}$ & 1.0 \\
\hline $\mathrm{NaOH}$ & 4.7 \\
\hline $\mathrm{NaAl}(\mathrm{OH})_{4}$ & 0.3 \\
\hline $\mathrm{NaNO}_{2}$ & 0.0 \\
\hline Total Na $^{+}$ & 6.0 \\
\hline
\end{tabular}

* The levels of $\mathrm{Al}$ and $\mathrm{Si}$ in these solutions were probably higher at the end of the sorption tests due to the dissolution of some of the solids used in the testing.

Table 3.3 Composition of salt solution 3, which was used in Test 5.*

\begin{tabular}{|c|c|}
\hline Component & Concentration (M) \\
\hline $\mathrm{NaNO}_{3}$ & 2.60 \\
\hline $\mathrm{NaOH}$ & 1.33 \\
\hline $\mathrm{Na}_{2} \mathrm{SO}_{4}$ & 0.521 \\
\hline $\mathrm{NaAl}_{4}(\mathrm{OH})_{4}$ & 0.429 \\
\hline $\mathrm{NaNO}_{2}$ & 0.34 \\
\hline $\mathrm{Na}_{2} \mathrm{CO}_{3}$ & 0.026 \\
\hline Total Na & 5.60 \\
\hline
\end{tabular}

* The levels of Al and Si in these solutions were not determined but they were higher than shown-due to the 7-day pre-equilibration of the solutions with their respective NAS solids. The Si and Al levels in the solutions after the sorption studies could have been as high as $0.06 \mathrm{M} \mathrm{Si}$. 


\subsection{Sorption Studies}

All of the sorption studies were performed with $1.1 \mathrm{~g}$ of NAS solids per $\mathrm{L}^{-1}$ of U(VI)-spiked solution. All U concentrations in the solutions were determined prior to use by inductivelycoupled plasma-mass spectroscopy (ICP-MS as listed in Table 3.4). The solutions were contacted with one of the NAS solids on an orbital shaker oven for up to 1 week. Temperatures for the Tests 1 and 2 were $40^{\circ} \mathrm{C}$ whereas the remaining tests were performed at $25^{\circ} \mathrm{C}$. The solutions were sub-sampled at various times $(0.5,4,24$ and 168 hours $)$ during the tests - as designated in Table 3.4. Controls consisted of U(VI)-spiked salt solutions that were free of NAS solids. For Test 5, there was one control test performed for every solid tested. All other tests and test controls were performed in duplicate. A synoptic description of the tests is presented in Table 3.4.

Sampling involved filtering the U-containing slurries with a $0.45-\mu \mathrm{m}$ nylon syringe filter followed by the acidification of the solutions with $5 \mathrm{M}$ trace metal grade nitric acid and submittal for ICP-MS analyses. All samples were taken at room temperature. The samples from the tests performed at $40^{\circ} \mathrm{C}$ were filtered within 60 seconds of removal from the heated shaker over. Additional acid was required for some of the samples to dissolve any solids that formed upon acidification. The amount of acid added was recorded to account for the extra dilution.

Table 3.4 Design of Tests 1 through 5.

\begin{tabular}{|c|c|c|c|c|c|c|}
\hline Test & Salt Solution & Conditions & $\begin{array}{c}\text { U Conc.* } \\
\text { (mg/L) }\end{array}$ & $\begin{array}{l}\text { Study } \\
\text { Temp. } \\
\text { (deg. C) }\end{array}$ & $\begin{array}{c}\text { Samples } \\
\text { Pulled } \\
\text { (hours) }\end{array}$ & $\begin{array}{c}\text { Samples } \\
\text { Analyzed } \\
\text { (hours) }\end{array}$ \\
\hline 1 & 1 (No Al, Si) & Air & 0.23 & 40 & $0,0.5,4,24,168$ & 0,4 \\
\hline 2 & 1 (No Al, Si) & Air & 0.72 & 40 & $0,0.5,4,24,168$ & $0,0.5,4$ \\
\hline 3 & 1 (No Al, Si) & Argon (low CO2) & 6.42 & 25 & $0,0.5,4,24,168$ & $0,0.5,4$ \\
\hline 4 & $2(\mathrm{w} / \mathrm{Al}, \mathrm{No} \mathrm{Si})$ & Air & 0.23 & 25 & $0,0.5,4,24,168$ & $0,0.5,4^{* *}$ \\
\hline 5 & $3\left(\mathrm{w} / \mathrm{Al}, \mathrm{Si}\right.$, pre-equilib.) ${ }^{* * *}$ & Air & 0.16 & 25 & $0,0.5,4,24,168$ & $0,4,24$ \\
\hline
\end{tabular}

Page 16 of 31 
WSRC-TR-2002-00394, REVISION 0

\subsection{RESULTS}

\subsection{Sorption Studies}

The results of the sorption study tests that were preformed with solutions 1, 2 and 3 are presented in Table 4.1. Samples from the short-term contacted (0.5, 4 and 24 hours) were typically the first samples to be measured for U concentration by ICP-MS. These analyses of these samples, which included studies with all of the NAS phases showed that there was no loss of U upon contact with the NAS solids - suggesting U may have little affinity for the NAS solids.

Visual observations from sorption Tests 1 and 2 indicated that all of the NAS solids with the exception of the cancrinite dissolved during the first 24 hours of equilibration with the salt solutions. Therefore, the subsequent study was performed at $25^{\circ} \mathrm{C}$ (for Test 3 ), a temperature at which the solubility of the NAS solids was expected to be lower. However, the solids dissolved within the first day of the experiment and thus the samples obtained at or beyond 24 hours were not submitted for U analyses by ICP-MS.

Tests 4 and 5 (see Table 4.1) proved similar to the previous sorption tests in that little observable uptake of $U$ occurred during these experiments. The sorption of $U$ on zeolites is a rapid process ${ }^{1,2}$ and if operable, it should have occurred in these studies. Because no loss of $U$ from solution was observed, solid phase NAS samples from the sorption studies were not submitted for surface area, X-ray diffraction (XRD) or X-ray absorption fine-structure (XAFS) spectroscopic analyses as originally planned in the Technical Task Plans (WSRC-RP-200101102, Rev. 0, WSRC-RP-2002-00021, Rev. 1) associated with this U-NAS work. ${ }^{34,35}$ The low amount of $U$ sorption observed may be due to the use of freeze-dried (potentially less reactive solids) as opposed to solids that had not undergone drying prior to use.

\subsection{Dissolution Processes of Solids in Aqueous Solutions}

Due to the observed dissolution of the some of the NAS solids in this study, a review of dissolution processes will be presented. This section will be followed with a discussion of how these dissolution processes relate to the NAS solids used in this study. It will also discuss the dissolution and solubility of sparingly soluble $U$ solid phases that may form in evaporators and exist in saltcake.

\subsubsection{Steps of Dissolution and the Reactions that Control Dissolution}

Reactions at solid surfaces in the aqueous systems can result in the dissolution of solids, catalysis of other reactions and formation of new solid phases. These processes are typically affected by dissolved constituents for example, protons, metal ions and ligands [such as carbonate and oxalate $\left(\mathrm{C}_{2} \mathrm{O}_{4}{ }^{2-}\right)$ ions]. The dissolution of a solid surface in aqueous solutions involves four major processes: 1) detachment of ions from the surface, 2) diffusion of ions from the surface, 3) desorption of ions from the surface and 4) mass diffusion of ions from the surface. ${ }^{36}$

Page 17 of 31 
WSRC-TR-2002-00394, REVISION 0

Table 4.1 Results of sorption Tests 1 through 5.

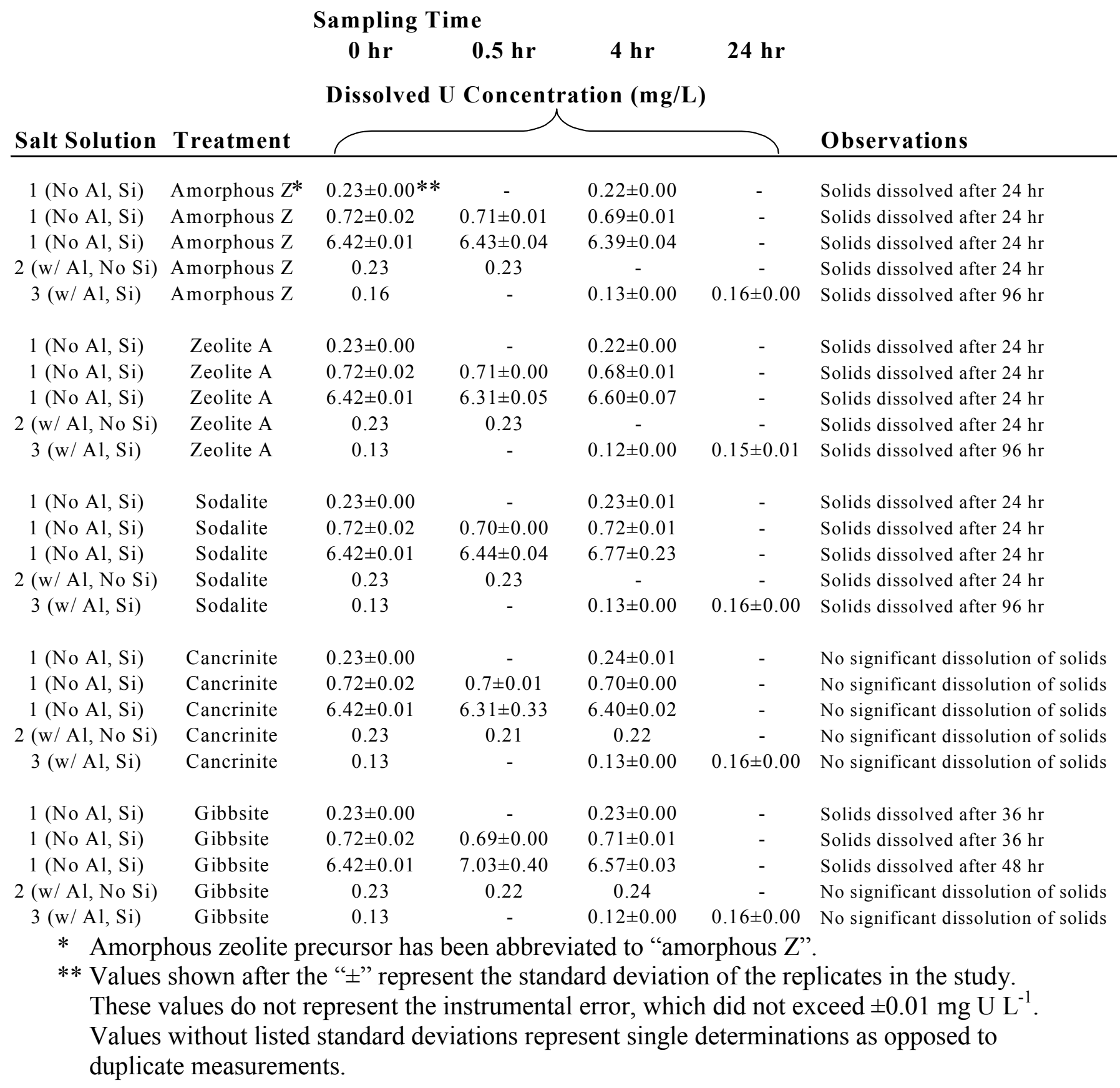

Page 18 of 31 
Most dissolution processes at the surface occur by hydration, ion-exchange and $\mathrm{pH}$-controlled (hydrolysis) reactions. Hydration reactions are mostly a function of water movement into the solid, pore size, and the bonding nature (covalent, ionic) of the solid constituents. Ionexchange reactions (of ligands, metals and cations) are subject to $\mathrm{pH}$, ligand/metal type and ligand concentration. The hydrolysis reactions are subject to changes in $\mathrm{pH}-$ particularly when surfaces exhibit $\mathrm{pH}$-dependent charge behavior. ${ }^{37}$ Ligands, protons or high hydroxide concentrations (above $\mathrm{pH} 12$ and beyond) may weaken the structure of a solid by adsorption thus, accelerating the dissolution of the solid. In contrast, some ligands (such as phosphate ion) can form strong surface complexes that block the release of solid constituents into the aqueous phase. In this case, ligands may decrease the dissolution rate of the solid by blocking surface sites. Dissolution reactions for solids with low solubility are usually surface-controlled or transport-controlled (also called diffusion-controlled). ${ }^{38}$ Solids such as the carbonates, halide salts and sulfate salts tend to be readily soluble and transport-controlled. ${ }^{9}$ Solids that possess transport-controlled dissolution properties are likely to dissolve faster in the presence of high flow rates or stirring rates than solids which have surface-controlled dissolution properties. In some cases, both control mechanisms may be operative.

\subsubsection{Site Reactivity during D issolution}

A decrease in the energy of activation at the solid surface usually accompanies dissolution. Hence, the dissolution process is related to structural site reactivity. For example, the adsorption of dissolved species is usually greatest at the most active surface sites on the solid (such as the "kink", "ledge", and "adatom" sites) and it is weakest at (relatively) flat, crystal terraces. Regeneration of active sites can be an important rate-determining step during dissolution. Bond order rearrangements of surface species may also influence the slow the release of solid constituents. Additionally, the sorption of metal ions (such as $U$ ) has been observed to slow the dissolution of the solid constituents by blocking surface sites. ${ }^{9}$

\subsubsection{Quantification of Dissolu tion Rates}

Experimentally, the determination of dissolution rates with respect to individual solution species at steady state can be described by the equation:

$$
R=d C / d t=k \sigma^{n}
$$

where: $R=$ dissolution rate $\left(\mathrm{M} \mathrm{s}^{-1}\right)$,

$C=$ concentration in solution $(\mathrm{M})$,

$t=$ time (s),

$k=$ reaction rate constant $\left(\mathrm{M} \mathrm{m}^{-2} \mathrm{~s}^{-1}\right)$,

$\sigma=$ mineral surface area $\left(\mathrm{m}^{2}\right)$, and

$n=$ effective order of the reaction.

The order, which describes the molecularity of the reaction can be determined by plotting the equation on a logarithmic plot. Generally, if the determined order of reaction is greater than 1 , 
the reaction is considered to fit a surface-controlled model instead of a diffusion-controlled model (where $\mathrm{n} \leq 1$ ). Hence, these surface-controlled reactions are typically slow in comparison to transport- or diffusion-controlled reactions. This equation may be expanded to an overall rate equation that includes such important components as ligand- or $\mathrm{pH}$-dependence:

$$
R_{\text {total }}=R_{H}+R_{L}+R_{H 2 O}
$$

where: $R_{\text {total }}=$ total rate (units vary with reaction order),

$R_{H} \quad=$ is the proton-promoted rate,

$R_{L} \quad=$ ligand-promoted rate, and

$R_{H 2 O}=$ hydration and $\mathrm{pH}$-independent rate term

This equation assumes the reactions occur (in parallel) at separate sites at the metal or actinide centers and concentrations of solution components remain far from equilibrium values. ${ }^{9}$

However at or near equilibrium, back reactions at the surface can occur (such as the precipitation of a new phase) and produce nonlinear dissolution rates. Near equilibrium, the overall dissolution rates are considerably slower than rates observed for systems, which are far from equilibrium.

The overall dissolution rates for metal oxides and aluminosilicates are typically linear - when the systems are far from equilibrium. ${ }^{9}$ Above zero point of charge (ZPC), the proton-promoted dissolution rates $\left(R_{H}\right)$ of these solids usually increase with increasing $\mathrm{pH}$ whereas below the $\mathrm{ZPC}$, the proton-promoted dissolution rates tend to increase with decreasing $\mathrm{pH}$. An example of this behavior is the dissolution of the aluminosilicate solid anorthite $\left(\mathrm{CaAl}_{2} \mathrm{Si}_{2} \mathrm{O}_{8}\right)$ as shown in Fig. 4.1 (adapted from Amrhein and Suarez (1988)]. ${ }^{39}$ This diagram shows that dissolution rates for anorthite is greatest at low and high $\mathrm{pH}$. In this example, below the $\mathrm{ZPC}$, protons adsorb to the surface and promote Si dissolution. Above the ZPC, hydroxide ions at the anorthite surface promote the dissolution of Si. The proton-promoted rate is nearly constant between $\mathrm{pH} 5$ and $8 .{ }^{39}$ Such behavior is likely to occur with some zeolites such as those that were labile in the salt solutions used in this study.

Dissolution rates with respect to total dissolved cations [such as $\mathrm{Al}(\mathrm{III})$ released during the dissolution of $\left.\mathrm{Al}_{2} \mathrm{O}_{3(\mathrm{~s})}\right]$ are often linear over time at a constant $\mathrm{pH}$ (Fig. 4.2). Figure 4.2 demonstrates the dissolution of alumina $\left[\delta-\mathrm{Al}_{2} \mathrm{O}_{3(\mathrm{~s})}\right]$ (by the release of dissolved $\mathrm{Al}$ ) as a function of oxalate concentration over time. In Figure 4.3, the ligand-catalyzed dissolution rate $\left(R_{L}\right)$ is shown to vary in the presence of various surface concentration of ligands. Hence, the slope of the dissolution rate can increase or decrease - depending on whether the ligands promote or inhibit the dissolution of the solid. 


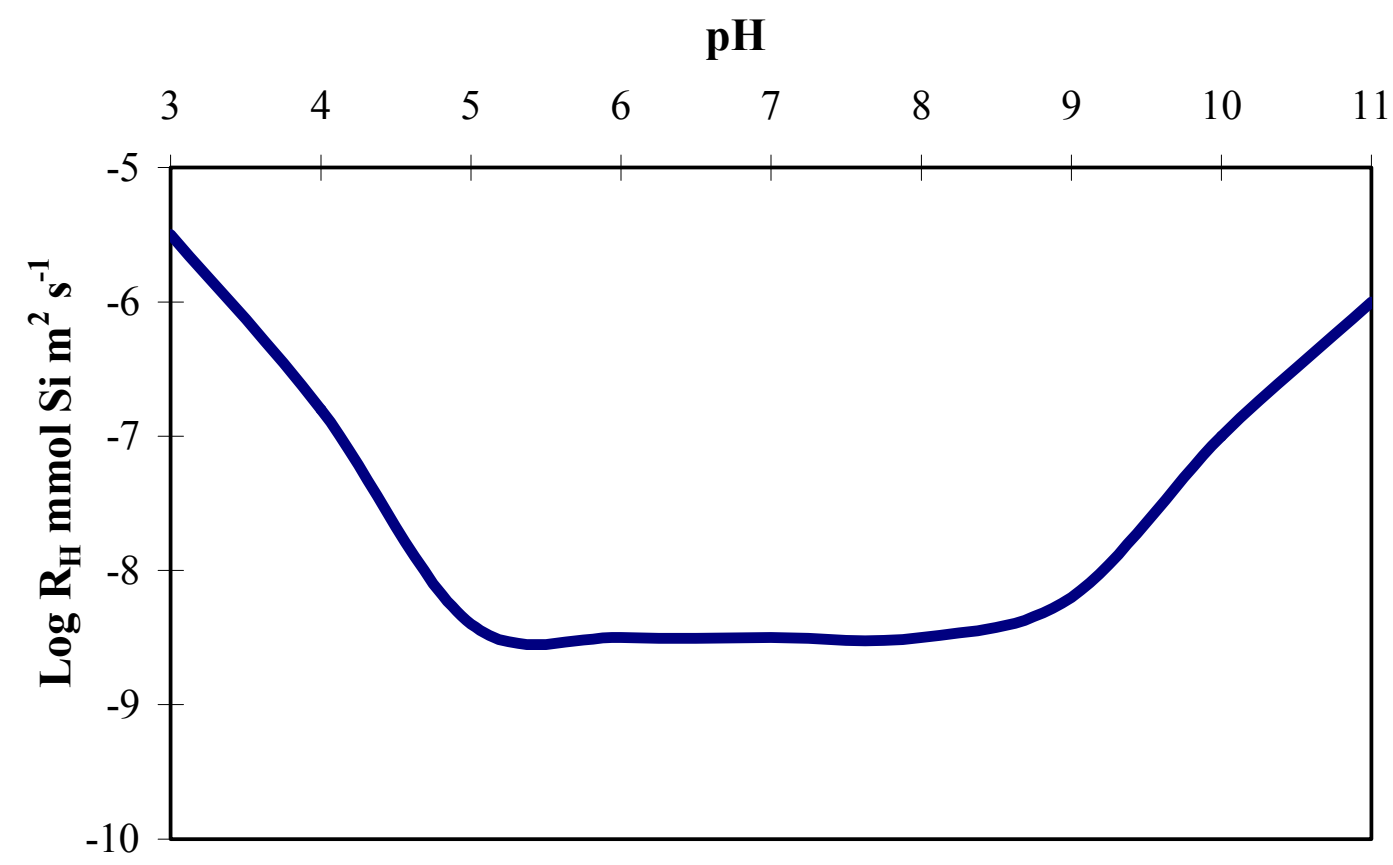

Figure 4.1 The influence of $\mathrm{pH}$ on the release of $\mathrm{Si}$ from the aluminosilicate anorthite $\mathrm{CaAl}_{2} \mathrm{Si}_{2} \mathrm{O}_{8}, \mathrm{ZPC}$ of 6.8). Simplified and adapted from Amrhein and Suarez (1988). ${ }^{39}$ 
WSRC-TR-2002-00394, REVISION 0

\subsubsection{Dissolution of NAS and Other Solids in the Tanks Farms}

The reactions for the dissolution of many sparingly soluble solids (specifically, solids that have low solubility in water) are usually surface-controlled and not transport-controlled. ${ }^{38}$ Surfacecontrolled reaction rates are often influenced by $\mathrm{pH}$ and the type and concentration of any ligand(s) or metals present. ${ }^{9}$ For the NAS solids, $\mathrm{pH}$-controlled (hydrolysis) reactions probably were facilitated for the rapid dissolution of the zeolites (specifically sodalite, amorphous zeolite precursor, gibbsite and zeolite A) that was observed in this study. The zeolites that dissolve readily in the HLW salt simulant solutions (that are undersaturated in Si and $\mathrm{Al}$ ) from this study are likely to have similar behavior to anorthite as shown in Figure 4.1. However, the dissolution rates of these solids were not determined in this study. Additional research would be required to quantify such processes and to examine the influence of various solution constituents (hydroxide, Si and Al concentrations) on dissolution rates of NAS or other solids of interest that exist in the tank farms.

During saltcake dissolution, some solids will dissolve more readily than other solids. Salts that dissolved as a function of mass transport (i.e., transport-controlled) will be most labile. In contrast, less soluble salts usually dissolve under surface-controlled conditions so they will remain undissolved for longer periods. Their dissolution can be enhanced by the presence of ligands (such as oxalate, citrate) and by extreme basicity or acidity. High concentrations of dissolved metals, hydrophobic moieties and other ligands (such as phosphate) can inhibit the dissolution of these solids. With regard to saltcake dissolution, by adjusting the solution properties, such by the addition of a reactive ligand, faster dissolution rates of sparingly soluble solids could be achieved. This process could help mitigate the potential for a criticality - such as during saltcake dissolution. However, the addition of a ligand must be compatible with any downstream processes.

As previously discussed, metals can sorb to surfaces and inhibit the dissolution of a solid by blocking surface sites The removal of $U$ from solution (i.e., sorption of $U$ ) during the dissolution of the amorphous zeolite precursor, zeolite A and sodalite, was not observed (see Table 4.1). This suggests that sorption did not occur or that sorption is slower than the rate of solids dissolution under the conditions tested. Additional tests are needed to conclusively rule out sorption of $\mathrm{U}$ onto the amorphous zeolite precursor, zeolite A and sodalite phases.

Page 22 of 31 


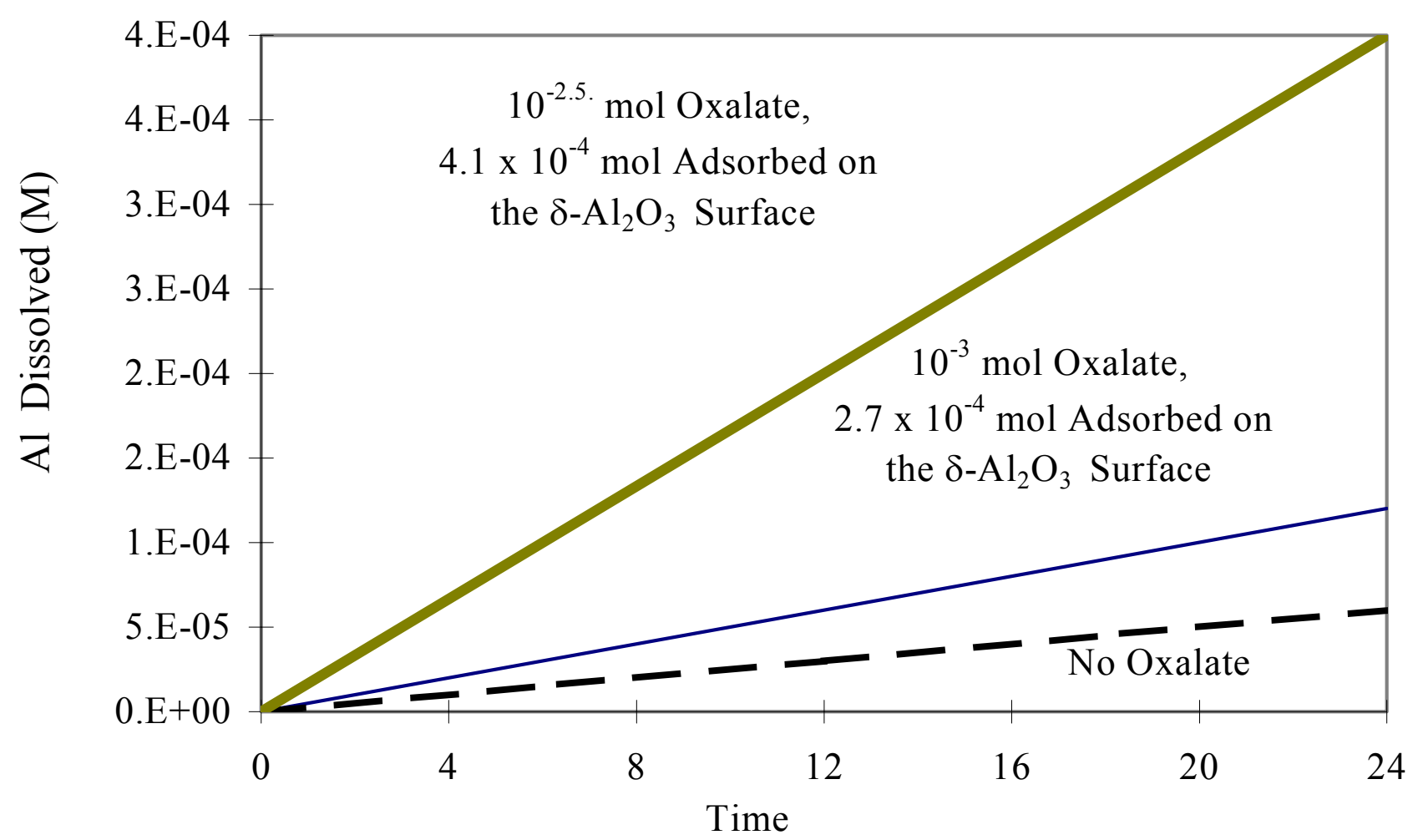

Figure 4.2 The influence of oxalate concentration on the release of $\mathrm{Al}$ from $\delta-\mathrm{Al}_{2} \mathrm{O}_{3}$. The dissolution of $\mathrm{Al}$ increases with increasing oxalate concentration (adsorbed and dissolved) in the system. (Adapted from Furrer and Stumm, 1986). ${ }^{40}$ 


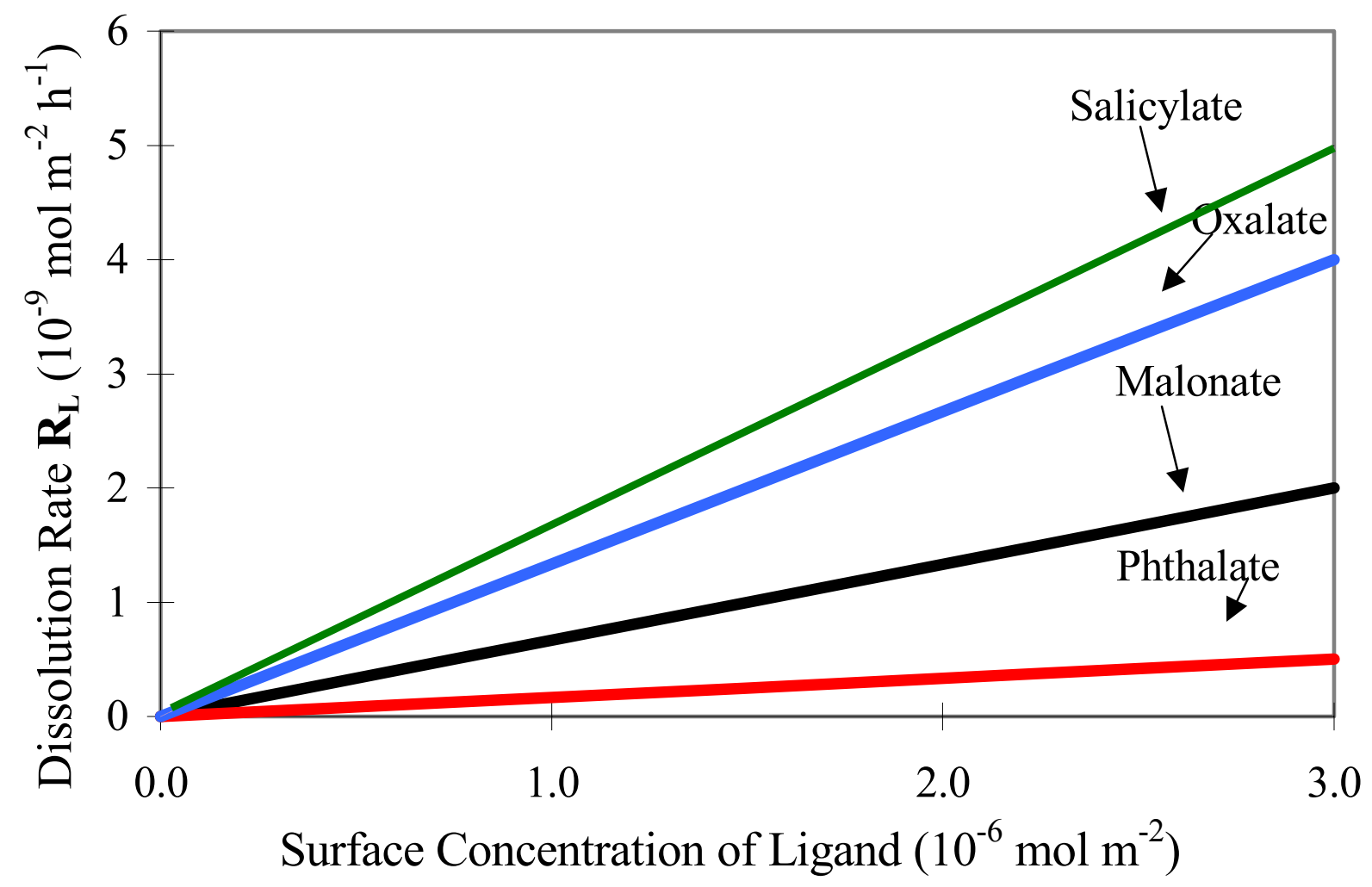

Figure 4.3 The influence of ligand type on the dissolution rate of $\delta-\mathrm{Al}_{2} \mathrm{O}_{3}$. The dissolution rate changes with respect to the type of ligand. (Adapted from Furrer and Stumm, 1986). ${ }^{40}$ 


\subsubsection{Stability of U Solids in Alkaline Solutions}

Little information is known about the dissolution of U-containing solids. ${ }^{41}$ However, the U solids that can be expected to form in highly basic, high Si and Al solutions are likely to be less soluble and dissolve much more slowly than most aluminosilicate (NAS) solids. ${ }^{42}$

A few studies have been conducted on the solubility of $U$ solids ${ }^{43,44,45,46}$ but some researchers deem these thermodynamic studies as incomplete because the research was performed from undersaturated to saturated conditions. $^{44,43}$ For example, Murphy (1997) presents several theories, which suggest that the U(VI)-silicate (such as soddyite, a uranyl silicate mineral and uranophane, a Ca uranyl silicate mineral) have increasing solubility with decreasing temperature or retrograde solubility. ${ }^{43}$ This would suggest that uranyl silicates are less soluble with temperature. This information suggests that in the presence of high dissolved Si, the precipitation of $U$ silicates is favored at high temperature, such as in the evaporators. The precipitation of U-silicates may also occur during sorption studies that are conducted with NAS solids that are in thermodynamic equilibrium with Al and Si. Little is known about the solubility of U-Si solids that form under highly alkaline conditions.

The low levels of $U$ that are typically observed in HLW salt solutions (a few tens of $\mathrm{mg} \mathrm{L}^{-1}$ ) suggests that $U$ solids are quite insoluble relative to other solids, such as some of the NAS solids. These differences in solubility and dissolution rates between U solids and some of the rapidly soluble NAS solids would favor U accumulation over NAS accumulation-particularly when the solution in contact with the solids is low in Al and Si. More studies are recommended to evaluate the dissolution rates of various $U$ solids that are known to form in saltcake during such treatments as saltcake dissolution. 


\subsection{CONCLUSIONS AND RECOMMENDATIONS}

Testing results indicated that uranium did not sorb onto cancrinite or gibbsite solids. Tests with other NAS materials, sodalite, zeolite A and the amorphous zeolite precursor also did not detect any evidence for uranium removal from the alkaline salt solutions. However, solids dissolution was significant during these sorption tests, which precludes us from concluding that sorption of uranium onto sodalite, zeolite A and the amorphous zeolite precursor does not occur. We recommend that additional tests be carried out under conditions that limit dissolution of these phases to confirm that sorption of uranium does not occur under strongly alkaline conditions.

The rapid dissolution of the zeolite A, sodalite and amorphous zeolite precursor solids solids observed in this study is note worthy. This finding reveals that the dissolution of some NAS solids would be favored when an evaporator feed that is low in $\mathrm{Al}$ and/or in Si is introduced into an evaporator that contains pre-existing NAS scale or when a plugged line is flushed with wash water. Dissolution of uranium solids produced upon evaporation of HLW solutions has not been extensively investigated. Given the differences in solubilities and dissolution rates for the NAS and uranium solids, we recommend that a study of their dissolution kinetics be undertaken to better understand conditions important to the evaporation of liquid waste solutions and the retrieval of saltcake for permanent disposal. These studies would need to be conducted under conditions that are not close to equilibrium so that back reactions at the NAS and U surfaces are minimized.

\subsection{QUALITY ASSURA NCE}

The following documents govern the work reported in this document.

- M. C. Duff and B. Croy, "Task Technical and Quality Assurance Plan for the Evaluation of Uranium Sorption on Sodium Aluminosilicate Structures," WSRC-RP-2001-01102, Rev. 0, December 27, 2001.

- Notebook WSRC-NB-2002-00042 (M. C. Duff) contains the experimental data obtained from this work.

\subsection{ACKNOWLEDGEMENTS}

The author thanks R. Edwards (WSRC), S. Reboul (WSRC), B. Van-Pelt (SRTC), D. T. Hobbs (SRTC), L. Oji (SRTC), S. Rosencrance (SRTC), W. Wilmarth (SRTC) and W. Tamosaitis (SRTC) for their assistance, support and ideas. Carol M. Jantzen (SRTC), J. F. Ortaldo (WSRC) and E. Lahoda (Westinghouse) provided helpful information about the $2 \mathrm{H}$ evaporator history. Mrs. B. Croy (SRTC) provided excellent laboratory assistance in the sample preparation. Mrs. C. Pierce (WSRC) provided our health physics support in the laboratory and worked with us so that the work could be performed safely and expediently. 
WSRC-TR-2002-00394, REVISION 0

\subsection{REFERENCES}

${ }^{1}$ Aky1l, S., Aslani, M. A. A., Ǒlmez, Ş. and Eral, M. (1996). Kinetic studies of uranium(VI) adsorption on a composite ion exchanger. J. Radioanal. Nucl. Chem. Lett. 213, 441-450.

${ }^{2}$ Akyıl, S., Aslani, M. A. A. and Aytaş, Ş. (1998). Distribution of uranium on zeolite X and investigation of thermodynamic parameters for this system. J. Alloys Cpds. 271/273, 769-773.

${ }^{3}$ There are numerous forms of cancrinite and sodalite, such as the nitrated forms in contrast to forms, which contain other anions such as carbonate. These anions help to account for charge balance. Generic forms of these zeolites are used here for simplicity.

${ }^{4}$ Jantzen, C. M., Laurinat, J. E. and Brown, K. G. (2002). Thermodynamic Modeling of the SRS Evaporators: Part I. The 2H and 3F Systems. WSRC-TR-2002-00293, Rev. 1.

${ }^{5}$ Jantzen, C. M., Laurinat, J. E. and Brown, K. G. (2001). Thermodynamic Modeling of the SRS Evaporators: Part II. The 3H System. WSRC-TR-2001-00155, Rev. 1.

${ }^{6}$ Ortaldo, J. F. (2000). SRS Interoffice Memorandum. HLW-DEN-2000-00330. Track \# 10080.

${ }^{7}$ Lahoda, E. and Mazzoccoli, J. (2001). Study of Silicate Control Methods for the Department of Energy. STD-01-CP-0021. Final Report 1. Westinghouse Science and Technology Department. June 25, 2001.

${ }^{8}$ Karraker, D. G. (1993). Uranium Solubility Studies During Waste Evaporation, WSRC-TR-93-433, Rev. 0, August 16, 1993.

${ }^{9}$ Stumm, W. (1992). Chemistry of the Solid-Water Interface: Processes at the Mineral-Water and Particle-Water Interface in Natural Systems. Wiley-Interscience, NY.

${ }^{10}$ McBride, M. B. (1994). Environmental Chemistry of Soils. Oxford Press, NY.

${ }^{11}$ Due to the small nature of nanoparticles, they often have more atoms at the solid-water interface than inside the solid. The use of spectroscopic techniques to elucidate the exact location of sorbing metals in such solids may potentially result in an inability to determine whether the metal is in an interlayer or vacancy site.

${ }^{12}$ Sorption reversibility is tested by leaching the metal loaded solid with a target metal-free solution that has the same properties (i.e. ionic strength, background electrolytes, $\mathrm{pH}$ etc...) and measuring the leachate solution to determine whether any target metal is released. Specifically adsorbed species are typically not leached with lower ionic strength solutions and specific adsorption processes are not a function ionic strength (assuming the electrolytes do not interact with the sorbed species via complexation etc.). Outer-sphere species can be readily removed with solutions of low ionic strength or solutions that contain high concentrations of a cation that has a higher affinity for the surface than the outer-sphere species. Therefore, outer-sphere sorption is viewed as reversible and a function of ionic strength.

${ }^{13}$ Specific adsorption is typically a function of surface charge properties. When a participating surface has a charge that varies with solution $\mathrm{pH}$, specific adsorption exhibits $\mathrm{pH}$-dependent behavior. For example, a surface that is highly protonated (at low $\mathrm{pH}$ ) will have more affinity for negatively-charged

Page 27 of 31 
species (such as the negatively-charged species). As the $\mathrm{pH}$ decreases, the surface charge of $\mathrm{pH}$ dependent charged surfaces becomes more negative and the uptake of positively charged species is favored. Therefore, the surface of metal oxides for example specifically adsorbs more positively charged species as the solution $\mathrm{pH}$ increases. However, this behavior is generalized. As the solution $\mathrm{pH}$ increases sorbing species undergoes a change in speciation - such as hydrolysis. In this case, the amount of specific adsorption becomes a function of solution speciation. Ion exchange resins that sorb free ions of actinides (e.g., the non-hydrolyzed $\mathrm{Pu}^{4+}$ species) at high $\mathrm{H}^{+}$concentrations (i.e., low $\mathrm{pH}$ ) will release sorbed $\mathrm{Pu}^{4+}$ species when the solution $\mathrm{pH}$ is raised - due to the hydrolysis of the sorbed $\mathrm{Pu}^{4+}$ (e.g., $\mathrm{Pu}(\mathrm{OH})_{3}{ }^{+}, \mathrm{Pu}(\mathrm{OH})_{2}{ }^{2+}$ ). The hydrolysis species have a lower overall charge and their size (as an ion group) is larger than the free ion-making them have a lower affinity for the surface. Other processes [particularly for $\mathrm{U}(\mathrm{VI})$ ] that can influence sorption are metal complexation with ligands (i.e., with carbonate ion) or in the case of anions, protonation (e.g., $\mathrm{PO}_{4}{ }^{3-}+\mathrm{H}^{+} \rightarrow \mathrm{HPO}_{4}{ }^{2-}$ ). Specific adsorption processes are a function of many variables.

${ }^{14}$ Olguin, M. T., Duque, J., Pomés, R., Villafuerte-Castrejón, M. E., Sansores, L. E., Bosch, P. and Bulbulian, S. (1997). Characterization of $\mathrm{UO}_{2}{ }^{2+}$-exchanged Y zeolite. J. Radio. Anal. Nucl. Chem. 222, 235-237.

${ }^{15}$ No U-aluminate solid phases have been documented. If these phases form, other U phases, such as the oxides, hydroxides and silicates of $U$ are more likely dominate the speciation of solid phase $U$ under evaporator and salt solution conditions.

${ }^{16} \mathrm{Li}$, Y. and Burns, P. C. (2001). The structures of two sodium uranyl compounds relevant to nuclear waste disposal. J. Nucl. Mater. 299, 219-226.

${ }^{17}$ Hobbs, D. T., Bronikowski, M. G., Edwards, T. B. and Pulmano, R. L. (1999). Final Report on Phase III Testing of Monosodium Titanate Adsorption. WSRC-TR-99-00134, May 28, 1999.

${ }^{18}$ Duff, M. C., Hobbs, D. T. and Fink, S. D. (2002). Permanganate Treatment Optimization Studies for Strontium and Actinide Removal from High Level Waste Simulants, WSRC-TR-2002-0027, Jan. 14, 2002.

${ }^{19}$ Crespo, M. T., Gascon, J. L. and Acena, M. L. (1993). Techniques and analytical methods in the determination of uranium, thorium, plutonium, americium and radium by adsorption on manganese dioxide. Sci.Tot.Environ. 130, 383-391.

${ }^{20}$ Duff, M. C., Hunter, D. B., Hobbs, D. T., Jurgensen, A. and Fink, S. D. (2002). Characterization of Sorbed Plutonium, Neptunium, Strontium on Manganese Solids from Permanganate Reduction. WSRCTR-2002-00366, Rev. 0, Sept. 19, 2002.

${ }^{21}$ Clark, D. L., Conradson, S. A., Donohoe, R. J., Keogh, D. W., Morris, D. E., Palmer, P. D., Rogers, R. D. and Tait, C. D. (1999). Chemical speciation of the uranyl ion under highly alkaline conditions, synthesis, structures and oxo ligand exchange dynamics. Inorg. Chem. 38, 1456-1466.

${ }^{22}$ Hsi, C-K. D. and Langmuir, D. (1985). Adsorption of uranyl onto ferric oxyhydroxides: Applications of the surface complexation site-binding model. Geochim. Cosmochim. Acta 49, 1931-1941.

${ }^{23}$ Duff, M. C. and Amrhein, C. (1996). Uranium(VI) adsorption on goethite and soil in carbonate solutions. Soil Sci. Soc. Amer. J. 743, 1393-1400.

Page 28 of 31 
${ }^{24}$ Duff, M. C., Hunter, D. B., Hobbs, D. T., Barnes, M. J. and Fink, S. D. (2001). Characterization of Sorbed Uranium, Plutonium and Neptunium on Monosodium Titanate. WSRC-TR-2001-00356, Sept. 19, 2001.

${ }^{25}$ Prikryl, J. D., Jain, A, Turner, D. R. and Pabalan, R. T. (2001). Uranium(VI) sorption behavior on silicate mineral mixtures. J. Contam. Hydrol. 47, 241-253.

${ }^{26}$ Godelitsas, A., Misaelides, P., Filippidis, A., Charistos, D. and Anousis, I. (1996). Uranium sorption from aqueous solutions on sodium-form of HEU-type zeolite crystals. J. Radio. Anal. Nucl. Chem. Art. 208, 393-402.

${ }^{27}$ Godelitsas, A., Misaelides, P., Filippidis, A., Charistos, D. and Anousis, I. (1996). Uranium sorption from aqueous solutions on sodium-form of HEU-type zeolite crystals. J. Radio. Anal. Nucl. Chem. Art. 208, 393-402.

${ }^{28}$ Reich, T., Moll, H., Denecke, M. A., Geipel, G. Bernhard, G., Nitsche, H., Allen, P. G., Buchner, J. J., Kaltsoyannis, N., Edlestein, N. M. and Shuh, D. K. (1996). Characterization of hydrous uranyl silicate by EXAFS. Radiochim. Acta 74, 219-223.

${ }^{29}$ Duff, M. C., Coughlin, J. U. and Hunter, D. B. (2002). Uranium co-precipitation with Fe oxide minerals, Geochim. Cosmochim. Acta 66, 3533-3547.

${ }^{30}$ Bargar, J. R., Reitmeyer, R., Lehnart, J. J. and Davis, J. A. (2000). Characterization of U(VI)carbonato ternary complexes on hematite: EXAFS and electrophoretic mobility measurements. Geochim. Cosmochim. Acta. 64, 2737-2749.

${ }^{31}$ Mensah, A., Li, J. and Zbik, M. (2002). The Chemistry, Crystallization, Physicochemical Properties and Behavior of Sodium Aluminosilicate Solid Phases. WSRC/ERDA GA00083, June 7, 2002.

${ }^{32}$ Highly alkaline salt solutions can remove atmospheric $\mathrm{CO}_{2(\mathrm{~g})}$ from air. The dissolved carbonate that results from this process can then serve as a strong complexant of $\mathrm{U}(\mathrm{VI})$, by forming [such as $\left.\mathrm{UO}_{2}\left(\mathrm{CO}_{3}\right)_{3}{ }^{4-}\right]$. These highly soluble U(VI)-carbonate complexes are known to have limited affinities for solid phases such as the Fe oxides (hematite and goethite).

${ }^{33}$ Aluminum and silicon were not included in the initial sorption experiments because they could potentially promote the conversion of the NAS solids to other phases. The rapid dissolution of these NAS solid phases (specifically, sodalite, zeolite A, gibbsite and amorphous zeolite material) was not anticipated-particularly since theses solids were made under highly basic solutions. However, once the rapid dissolution of some of the NAS solids was observed in most of the treatments, a lower test temperature and a salt solution containing higher $\mathrm{Al}$ and $\mathrm{Si}$ levels were selected for additional testing.

${ }^{34}$ Duff, M. C. and Croy, B. (2001). Task Technical and Quality Assurance Plan for the Evaluation of Uranium Sorption on Sodium Aluminosilicate Structures. WSRC-RP-2001-01102, Rev. 0, December $27,2001$.

${ }^{35}$ Duff, M. C., Hunter, D. B. and Croy, B. (2002). Task Technical and Quality Assurance Plan for XAFS Analyses on Solids from Sorption and Co-Precipitation Studies with Uranium Sodium Aluminosilicates. WSRC-RP-2002-00021, Rev. 1, February 13, 2002.

Page 29 of 31 
${ }^{36}$ Zhang, J-W. and Nancollas, G. H. (1990). Mechanisms of growth and dissolution of sparingly soluble salts. Reviews in Mineralogy. Mineral. Soc. of Amer. pp. 365-396.

${ }^{37}$ In solution, protons can also adsorb to metal oxide, oxyhydroxide, silicate and phosphate surfaces. Hence, the solution $\mathrm{pH}$ affects the overall surface charge of the solid:

$$
\begin{aligned}
& \equiv \mathrm{Fe}-\mathrm{OH}+\mathrm{H}^{+}<\longrightarrow=\mathrm{Fe}-\mathrm{OH}_{2}^{+} \\
& \equiv \mathrm{Fe}-\mathrm{OH}<\longrightarrow \equiv \mathrm{Fe}-\mathrm{O}^{-}+\mathrm{H}^{+}
\end{aligned}
$$

where "三" denotes a surface of an Fe oxide $(\mathrm{FeOH})$.

This tendency of metal surfaces to be influenced by $\mathrm{pH}$ is referred to as $p H$-dependent surface charge behavior. Hence, these solids possess a net-positive surface charge at low $\mathrm{pH}$ and a net-negative surface charge at high $\mathrm{pH}$. The solids have a zero point of charge (ZPC, a point at which the net negative surface charge is equal to the net positive surface charge) which can be determined by a potentiometric titration. The ZPC is closely related to the zeta potential and it can be determined by applying an electric field to a solid aqueous suspension and measuring the resultant particle velocity in that field. Dissolved molecules such as ligands often have a heterogeneous spatial distribution of charge. In solution, the negatively-charged functional groups of molecules are attracted to positively-charged actinide species such as $\mathrm{UO}_{2}{ }^{2+}$, a dissolved U(VI) species:

$$
\mathrm{UO}_{2}^{2+}+\mathrm{L}^{-}<\longrightarrow \mathrm{UO}_{2} \mathrm{~L}^{+}
$$

where "L" denotes a ligand.

It is these complexes which can significantly increase the solubility of actinides - particularly in the case of carbonate and hexavalent $U$. When a ligand contains more than one functional group, it can act as a chelate by forming two or more distinct bonds with the actinide. For simplicity, the term ligand will be used - regardless of the bonding nature of the complexes to be discussed.

Once formed, actinide-ligand complexes may be adsorbed to surfaces:

$$
\equiv \mathrm{Fe}-\mathrm{OH}+\mathrm{L}^{-}+\mathrm{UO}_{2}^{2+}<\longrightarrow \equiv \mathrm{Fe}-\mathrm{L}-\mathrm{UO}_{2}^{2+}+\mathrm{OH}^{-} .
$$

It is adsorbing associations between ligands or protons, metal ions and surfaces (as in reaction 4) which are likely to influence the dissolution of sparingly soluble solids.

${ }^{38}$ For surface-controlled, surface reactions are the rate-determining step in the dissolution process whereas transport-controlled reactions are a function of diffusion or the mass-transfer of key dissolved constituents to the solid water interface.

${ }^{39}$ Amrhein, C. and Suarez, D. L. (1988). The use of a surface complexation model to describe the kinetics of ligand-promoted dissolution of anorthite. Geochim. Cosmochim. Acta. 52, 2785-2793.

${ }^{40}$ Furrer, G. and W. Stumm. (1986). The coordination chemistry of weathering: I. Dissolution kinetics of $\delta \mathrm{AlO}_{3}$ and BeO. Geochim. Cosmochim. Acta. 50, 1847-1860.

${ }^{41}$ Bruno, J., Casas, I. and Puigdomenech, I. (1991). The kinetics of dissolution of $\mathrm{UO}_{2}$ under reducing conditions and the influence of an oxidized surface layer $\left(\mathrm{UO}_{2+\mathrm{x}}\right)$ : Application of a continuous flowthrough reactor. Geochim. Cosmochim. Acta. 55, 647-658.

Page 30 of 31 
${ }^{42}$ Boley, C. S., Thompson, M. C., Wilmarth, W. R. and Brown, K. G. (2000). Technical Basis for the 242-16H Evaporator Cleaning Process. WSRC-TR-2000-00211.

${ }^{43}$ Murphy, J. W. (1997). Retrograde solubilities of source term phases. Mater. Res. Symp. Proc. Ser. 465, 713-720.

${ }^{44}$ Murphy, J. W and Pabalan, R. T. (1995). Review of empirical thermodynamic data for uranyl silicate minerals and experimental plan. Prepared for the Nucl. Reg. Comm. by the Center for Nucl. Waste Reg. Analyses, San Antonio, TX. June.

${ }^{45}$ Nguyen, S. N. et al., (1992). Standard Gibbs free energies of formation at the temperature 303.15-K of 4 uranyl silicates: soddyite, uranophane, sodium boltwoodite, and sodium weeksite. J. Chem. Thermo. 24, 359-376.

${ }^{46}$ Moll, H. et al. (1995). Synthesis and characterization of uranyl orthosilicate $\left(\mathrm{UO}_{2}\right)_{2} \mathrm{SiO}_{4} \cdot 2 \mathrm{H}_{2} \mathrm{O} . J$. Nucl. Mater. 227, 40-49. 